Article

\title{
Community Attachment Formation and Its Influence on Sustainable Participation in a Digitalized Community: Focusing on Content and Social Capital of an Online Community
}

\author{
Sungwook Lee ${ }^{1}$ and Do-Hyung Park ${ }^{2, *(D)}$ \\ 1 LG CNS Co., Ltd., Seoul 07795, Korea; sw1031@gmail.com \\ 2 School of Management Information Systems, Kookmin University, Seoul 02707, Korea \\ * Correspondence: dohyungpark@kookmin.ac.kr
}

Received: 18 April 2019; Accepted: 21 May 2019; Published: 23 May 2019

check for updates

\begin{abstract}
Individuals' lives and behaviors progressively change as information technology evolves. Through the rapid growth of information technology, individuals can access abundant information and virtual networks and create online communities for information and knowledge exchange and other intellectual pursuits. Some of the most important aspects of community success involve the engagement, participation, and active discussion of and among community members. This study focuses on the user-generated content (UGC) community and explores the mechanism for formation of community attachment from the perspective of the content capital and social capital of community members. In addition, this study demonstrates the moderating effect of membership duration on the mechanism of community attachment formation. Finally, this study reveals that the attachment formed with content and social capital can affect the decision to either continue to participate in a current UGC service site, or move to an alternative site.
\end{abstract}

Keywords: online community; attachment; user-generated content; sustainable participation

\section{Introduction}

Individuals' lives and behaviors progressively change as information technology evolves. Through the rapid growth of information technology, individuals can access abundant information and virtual networks and create virtual spaces (i.e., online communities) [1] for activities such as information and knowledge exchange [2], and other intellectual pursuits [3]. In this era of big data [4], the creation and sharing of content by and among individuals has become popular. The product of this new cultural development and revolution is known as User-generated content (UGC) [5].

Online communities are defined as the digitalized community where people with complementary or common interests gather to share information and contents via the Internet [6]. An online community offers new channels for consumers, employees, and business partners to connect $[7,8]$, provides sources of product innovation and consumer support $[9,10]$, and plays a role as a platform for new business models [11]. In addition, community members obtain useful information [12,13], emotional support [14], venues for sharing their own content [15], and channels to build up their social networks [16].

An important aspect of online community success is the engagement of community members (i.e., member participation and retention) [17]. Previous studies on online communities revealed that engaging community members requires member attachment, referring to members' affective connection to, and care for, an online community in which they are involved [6,17]. Community members with strong attachments to their online community proactively provide valuable content [18], answer other members' questions [19], and increase the value of current community content [20]. It is 
especially critical for UGC service providers to lead and guide members toward a strong community attachment because the continuous acquisition of secure, high-quality content is an important core factor for an online site's survival, as well as success [21,22]. Therefore, UGC service providers should understand the mechanism and factors that affect community attachment as a means to retain members.

Community attachment is formed and strengthened by group identity and interpersonal bonds between community members [17]. Individuals achieve group identity when they feel connected to a group's purpose or character [23]. Interpersonal bonds form when members develop relationships with other members [17]. For UGC communities, these two forms of attachment can be interpreted as "capital." Social capital theory argues that "capital" is defined as a resource that has the potential power to create and facilitate the economic or non-economic benefits to individuals. When the source of the resource is human, it is called human capital, and it is called social capital when it is based on social relationships, including people and organizations. The attachment based on interpersonal bonds is related to social capital, which a community member gains through social relationships with other community members. The attachment based on group identity and shared purpose is linked to content capital, which a community member creates and shares through his or her own effort, for a community goal. In this study, content capital refers to content existing in the community, which is either contributed by an individual himself or herself or uploaded by community members with shared interests. UGC communities with vibrant practices of content sharing and member-relationship development facilitate content creation and friendship formation, which accumulate and become community assets.

This study focuses on the UGC and explores the mechanism for formation of community attachment from the perspective of the content capital and social capital of community members. In addition, this study shows the moderating effect of membership duration on the mechanism of community attachment formation. Finally, this study reveals that the attachment formed with content and social capital can affect the decision to either continue participating in a current UGC service site or move to an alternative site, which is directly linked to community sustainability. Sustainability can be seen as a blend of the present and future for ongoing sustainable development. The concept of community sustainability can be thought of as operating a current community effectively and efficiently in order to "harmonize current and future members." This study suggests that community sustainability can be achieved based on both the content of current members accumulated so far (e.g., content capital) and the possibility of future growth and expansion through community members (e.g., social capital). For this sustainability, the most important thing is that current members feel a sense of psychological ownership in the community, have an attachment to the community, and have an intention of sustainable participation. This study focuses on the formation of community attachment and the role of community attachment for the purpose of continuous use.

\section{Theoretical Background and Hypotheses}

\subsection{Content and Social Capital for Community Attachment}

Starting in 1985 with a pioneer online community, thousands of online communities and social networking services have emerged. Some of the early communities still survive and have been growing dramatically in terms of the number of members. Others have disappeared due to lack of participation. Studies of online communities propose guidelines and success factors derived from various research areas, including management, sociology, and psychology. Rheingold [24] describes online communities from a social perspective as "social aggregations that emerge from the Net when enough people carry on public discussions long enough, with sufficient human feeling to form webs of personal relationships in cyberspace." It is emphasized that individuals form strong and lasting friendships online. In social psychology, Blanchard and Markus [25] define online communities as "groups of people who interact primarily through computer-mediated communication and who identify with and have developed feelings of belonging and attachment to each other." From a "sense of community" 
perspective, they stressed members' feelings toward other members and community attachment. Lee et al. [26] consider cyberspace, information and communication technology, member-driven content, members' interaction, and relationship formation as important components of an online community. The information system with which this research deals is an online community service in which people with a common interest gather in a web environment to share their content and receive feedback. Here, individuals can share a variety of content items, for example, personal photographs, personalized short movies, webtoons, and even novels. Such online services are active and popular in Asia under the title "Café Community." An individual uploads his or her own UGC, and other community members generally perform activities to evaluate, encourage, and give feedback on the content. Occasionally, contests and events are held in the community to encourage the activities of members. Useful information related to the café theme may also be provided, and a company selling a product or service related to the café theme tends to sponsor powerful communities such as a power blogger.

Although many studies point out community attachment as an important factor for community success, only a few studies have dealt with community attachment. The study conducted by Blanchard and Markus [25] focused on the sense of community, which included community member's feeling of belonging to a group, safety from a group, and attachment (i.e., psychological ownership) to a group. These positive feelings lead community members to establish sustainable and desirable relationships with other members and make them regard the group as a root of functional and emotional support. In general, there are two types of attachment: (1) Identity-based attachment targeting a group itself within the community; (2) bond-based attachment toward individual members [17]. Based on social psychological theory, they showed that community members form identity-based attachment by identification with the whole community and bond-based attachment by getting to like individual members. Both types of attachment increase members' active participation, their greater commitment to it, and their favorable evaluation of the community.

From the perspective of bond-based attachment formation, the social capital of a member within an online community may determine his or her community attachment. Social capital refers to the characteristics of a social structure that promotes action within the structure [27]. Social capital develops and accumulates as participation in personal relationships, creating resources that people can use to pursue their interests [28]. Wellman [29] showed that online communication and interaction have positive effects on the development of social capital. According to a study of the impact of online communities on society [30], online communities can promote strong social relationships, trust, and reciprocity. As a result, online communities can guarantee sufficient social capital leading participation in social action to achieve collective goals. Additionally, Liao and Chou [31] showed that social capital positively contributes to the attitudes and intentions of knowledge adoption of community members. Therefore, if community members have established sufficient social capital in an online community, they are likely to have community attachment.

From the perspective of identity-based attachment formation, online community members grow attached to a community as they construct community identity. Active participation and content contribution facilitate members' sense of community identity. Additionally, the history of their participation and contribution may be accumulated, which can be an asset for community members. Our research names the assets "content capital," which is defined as the historical content and activity log generated by a community member during his or her community membership. Content capital can be analogized to "switching costs," which embody the sacrifices and penalties that make it difficult for customers to change service providers [32], including not only financial damages, but also procedural and relational costs [33]. When customers perceive high switching costs, they feel "locked in" to their incumbent service provider. Therefore, if a member has accumulated a large amount of content capital during community membership, the member is more likely to feel a sense of community identity, stay in the current community, and have an increased attachment to the community. The effect of content capital on community attachment is likely to be much stronger for UGC communities than other sites. 
Since attachment requires the interaction history with the attachment target [34], the more time the user spends in an online community, the greater the possibility of developing a community attachment. However, perhaps more than just membership duration, past experience (i.e., quality and quantity of active participation, relationships, and content contribution) within a community is critical for attachment formation [35]. We expect that membership duration moderates the effect of social and content capital on community attachment, but only indirectly affects community attachment. Following are our hypotheses based on the previously reviewed literature (see Figure 1).

Hypothesis 1 (H1). Social capital in the current community increases the level of attachment to the current community.

Hypothesis 2 (H2). Content capital in the current community increases the level of attachment to the current community.

Hypothesis 3 (H3). The longer the membership duration in the current community, the stronger the effect of social capital on attachment to the current community.

Hypothesis 4 (H4). The longer the membership duration in the current site, the stronger the effect of content capital on attachment to the current community.

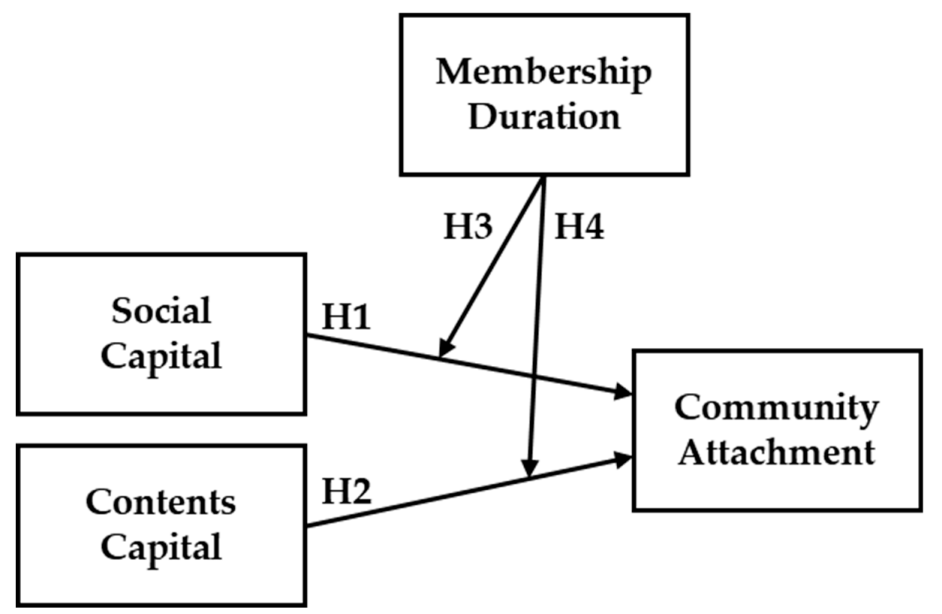

Figure 1. Research model of social capital, content capital, duration, and attachment.

\subsection{The Role of Community Attachment to Sustainable Usage}

Information system researchers have found out how individuals decide to accept and use a specific information technology system. Davis [36] said that two key variables-perceived usefulness and perceived ease of use toward a system - have an effect on users' attitude and determine their intention to use the system. A number of studies on information system adoption have been expanded by introducing new belief variables such as perceived joyfulness [37]. As for research on continuance usage, Bhattacherjee [38] suggested that continuous use of information technology is determined by users' satisfaction. Considering that UGC service is a type of information system, it can be anticipated that conclusions from former research can be applied in the UGC environment. Thus, it is expected that functional satisfaction on a certain UGC community positively affects continuous UGC sharing intention.

However, while there are limited alternatives to the traditional information system environment, there is an army of online UGC communities. If a UGC community with special features and functions emerge, community members are likely to switch from their current community to the new community by comparing the benefits of both communities. This study considered the "expected satisfaction" with an alternative UGC community along with satisfaction with a current UGC community. We can hypothesize the high possibility that community members are likely to remain with their current 
community when they find that their "expected satisfaction" with the alternative UGC site is lower than that of their current site.

Hypothesis 5 (H5). Satisfaction with the current site increases continuous UGC sharing intention on the current site.

Hypothesis 6 (H6). Expected satisfaction with an alternative site decreases continuous UGC sharing intention on the current site.

Based on the hypotheses above, if people decided their continuous UGC sharing intention only by functional satisfaction, only a few UGC service sites would survive. However, in real life, we find that many users stick with their original UGC service site, even though alternatives having possibly higher "expected satisfaction" exist. These examples suggest that more factors than just the comparison of satisfaction level should be involved for understanding continuous usage intention.

To explain this situation, this study hypothesized that attachment is involved in the decision process for the continuous UGC sharing intention because users who attached to a specific site would overestimate its quality. This explains why people stick to their original site even though there are many alternatives of better quality. Therefore, we can surmise that as the level of attachment increases, the effect of satisfaction with the current site on continuous UGC sharing intention increases. In contrast, the effect of expected satisfaction with the alternative site on continuous UGC sharing intention decreases.

We thought that users' attachment to their current sites could affect continuous UGC sharing intention, as users attached to their current UGC service sites could overestimate their quality level and possibly reject moving to alternative sites with objectively higher quality levels.

Therefore, we hypothesized that when a user is attached to a current UGC site, the satisfaction level with the current site affects his or her continuous UGC sharing intention more than other variables (Figure 2). To the contrary, in this situation, the effect of the expected satisfaction level with an alternative UGC site on the continuous UGC sharing intention with respect to the current site diminishes.

Hypothesis 7 (H7). The higher the level of attachment, the stronger the effect of satisfaction with the current site is on UGC continuous sharing intention with respect to the current site.

Hypothesis $\mathbf{8}$ (H8). The lower the level of attachment, the stronger the effect of expected satisfaction with an alternative site on UGC continuous sharing intention with respect to the current site.

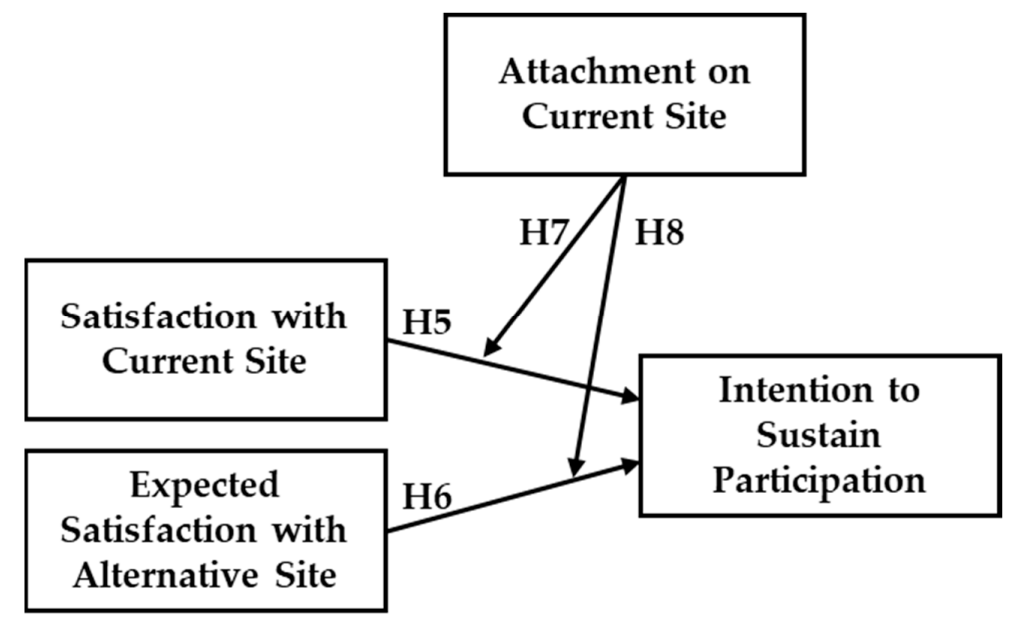

Figure 2. Research model of continuous participation, site satisfaction, and attachment. 


\section{Experiment 1: The Effect of Content and Social Capital on Site Attachment: The Moderating Role of Duration}

\subsection{Research Method}

\subsubsection{Design, Subjects, and Experimental System}

The purpose of experiment 1 was to find the effect of content capital and social capital on attachment to a UGC site. As we hypothesized, we examined the moderating role of duration. A $2 \times 2 \times 2$ factorial design was conducted for this experiment. The independent variables were: content capital (high vs. low); social capital (high vs. low); and duration (long vs. short). Two hundred people participated voluntarily. Their average age was about 30.9 years, and $52 \%$ were male. A reward of $\$ 5$ was given to all the participants who visited our experimental UGC site. Almost of them (about 98\%) already had UGC sharing experience in online communities. Participants were randomly assigned to each condition.

All participants visited the target virtual UGC site where the main activity was sharing Europe trip photos. This site was chosen for the experiment for three reasons. First, trips to Europe are so popular that most of the participants had the experience. This controls the effect related to the target of the UGC site contents. Second, photos are relatively more familiar to participants than videos in terms of required techniques. This reduces the unintended effect of participants' expertise with UGC creation. Finally, photos have clearer criteria for quality classification than videos. For example, some UGC is popular or well-known because of its funny actors, rather than skillfully produced scenes. By focusing on photos targeting European trips, we provided clearer criteria for the quality of the UGC.

The virtual UGC site had two main web pages. On one webpage, there were several photos of Europe created by UGC site members that participants could zoom in to view. When clicked, each photo and several items of feedback were magnified to a larger size. This virtual site mimicked real UGC sites, such as www.photopoints.com. The other webpage was the participants' MY PAGE, where information about the number of months a participant used the site was displayed, along with the contents already created and shared by the participant. A participant could click any content and read other members' feedback.

\subsubsection{Independent Variable}

Content capital is operationalized as the accumulated contents that a site member contributes to the site. In this experiment, it was manipulated by the number of images shown on MY PAGE. Three images were regarded as low content capital, while 161 images were regarded as high content capital.

Similarly, social capital is operationalized as friendliness, which indicates how many friendly members there are on a UGC site. In this experiment, it was manipulated by the number of friendly feedback comments shown on MY PAGE. Two feedback comments were regarded as low social capital, while at least 13 feedback comments were regarded as high social capital.

The duration is operationalized as how long a member acts as a site member. In this experiment, duration was manipulated as the time from site registration to the current day, which was displayed at the top of MY PAGE. Thirty-six months was regarded as a long duration, while one month was regarded as a short duration.

\subsubsection{Dependent Variable}

Site attachment is operationalized as the degree to which a site member is fond of, or loyal to, a site. Site attachment was measured on a 7-point numeric scale and was formed with questions of personal preference like "I am emotionally attached to my site," and questions of personal desire like "I am sentimental about my site." These questions were borrowed from the previous attachment study [39]. 


\subsubsection{Control Variables}

Personal UGC sharing experience and picture-related professionalism were controlled. There was no significant difference in these two variables $(\mathrm{F}<1, \mathrm{~ns})$. In addition, the difference in gender and age $(\mathrm{F}<1, \mathrm{~ns})$ and other personal characteristics, was not statistically significant $(\mathrm{F}<1, \mathrm{~ns})$.

\subsubsection{Experimental Procedures}

At the first stage of the experiment, the instruction "You are a member of the current UGC site for the purpose of sharing UGC-related photos of a European trip" was delivered. All participants entered the site via the homepage, which showed overall site characteristics, such as the total number of site members, best pictures on the site, and several messages from a freeboard (see Figure 3). Participants browsed the page, clicking links and reading content until he or she was familiar with the site. Five to ten minutes after browsing the homepage, the participant was asked to enter MY PAGE, where our manipulation was shown. Clicking the MY PAGE link provided the participant with information about duration manipulation at the top of the page. Content capital manipulation was found in the middle of the site. Depending on the level of content capital, different numbers of contents appeared. The participant browsed MY PAGE. When the participant clicked an item of contents, feedback from other site members was displayed. The feedback was, overall, positive and friendly, but the number of feedback comments differed depending on the level of social capital. Finally, all subjects were requested to provide site attachment, manipulation check, control check, and demographic information.

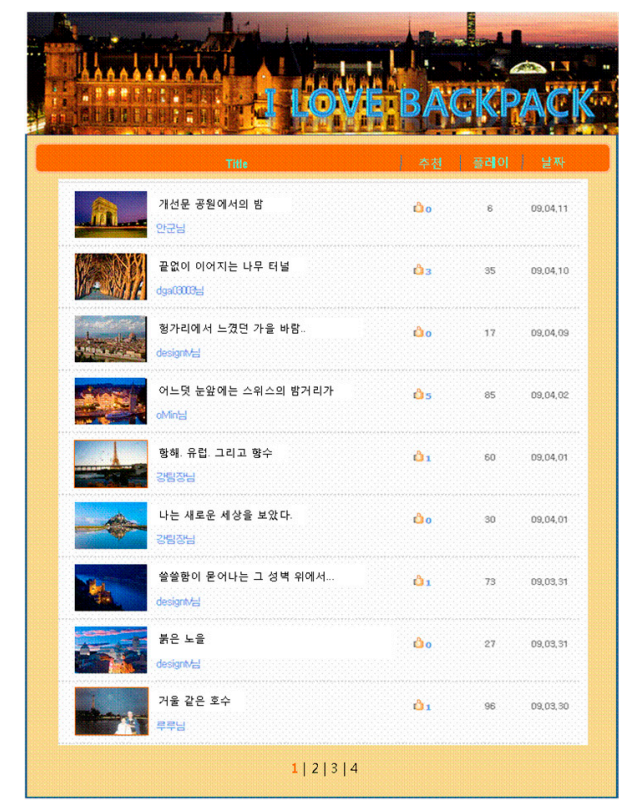

Figure 3. Main image of current user-generated content (UGC) service site.

\subsection{Research Results}

\subsubsection{Manipulation Checks}

The participants' two item responses designed for manipulation check on their perception of level of duration in the target site were averaged (Eigen Value $=1.71$, Cronbach's Alpha $=0.84$ ). An ANOVA analysis indicated the presence of the main effect of duration (F (1198) $=16.65, p<0.01)$. Participants exposed to the conditions of long duration perceived that they acted as a site member longer (the mean of long duration $=4.54$ ) than participants exposed to the conditions of short duration (mean of short duration $=3.79$ ). 
The participants' two item responses designed for manipulation check on their perception of level of content capital in the target site were averaged (Eigen Value $=1.78$, Cronbach's Alpha $=0.85$ ). An ANOVA analysis indicated the presence of the main effect of content capital $(F(1198)=33.38$, $p<0.01)$. Participants exposed to the conditions of high content capital perceived that they created and shared more content (the mean of high content capital $=4.61$ ) than participants exposed to the conditions of low content capital (mean of low content capital $=3.55$ ).

The participants' two item responses designed for manipulation check on their perception of level of social capital in the target site were averaged (Eigen Value $=1.89$, Cronbach's Alpha $=0.93$ ). An ANOVA analysis indicated the presence of the main effect of content capital (F $(1198)=81.80$, $p<0.01)$. Participants exposed to the conditions of high social capital perceived that they created and shared more content (the mean of high social capital $=5.03$ ) than participants exposed to the conditions of low social capital (mean of low social capital $=3.55$ ). In sum, all manipulations were successful.

\subsubsection{Hypothesis Testing}

We conducted a three-way ANOVA analysis on site attachment in order to test four hypotheses. Site attachment measured as two items (Eigen Value $=1.86$, Cronbach's Alpha $=0.92$ ) were averaged and used for the analysis. Table 1 shows the descriptive statistics of site attachment, and Table 2 shows the results of the ANOVA test.

Table 1. Descriptive statistics on site attachment of experiment 1.

\begin{tabular}{cccccc}
\hline Duration & Content Capital & Social Capital & Mean & Std. Deviation & N \\
\hline \multirow{3}{*}{ Short } & \multirow{3}{*}{ Low } & Low & 4.1000 & 1.05880 & 20 \\
& \multirow{3}{*}{ High } & High & 5.2667 & 0.86327 & 15 \\
& & Low & 3.7931 & 1.37916 & 29 \\
& \multirow{3}{*}{ Low } & High & 5.1250 & 0.75134 & 32 \\
\hline \multirow{3}{*}{ Hong } & Low & 2.7609 & 1.21421 & 23 \\
& & High & 5.1607 & 1.18676 & 28 \\
& & Low & 4.4677 & 0.98265 & 31 \\
& & High & 5.0455 & 1.40500 & 22 \\
\hline
\end{tabular}

Table 2. ANOVA test.

\begin{tabular}{ccc}
\hline Source & F-Value & Sig. \\
\hline Corrected Model & 14.323 & 0.000 \\
Intercept & 2966.512 & 0.000 \\
Duration & 1.680 & 0.197 \\
Content Capital & 3.038 & 0.083 \\
Social Capital & 69.724 & 0.000 \\
Duration $\times$ Content Capital & 9.678 & 0.002 \\
Duration $\times$ Social Capital & 0.533 & 0.466 \\
Content Capital × Social Capital & 6.383 & 0.012 \\
Duration $\times$ Content Capital × Social Capital & 9.183 & 0.003 \\
\hline
\end{tabular}

Social capital had the significant main effect (mean of low social capital $=3.83 \mathrm{vs}$. mean of high social capital $=5.13$ ), but the other effects were not significant. It resulted that $\mathrm{H} 2$ was accepted, but $\mathrm{H} 1$, $\mathrm{H} 3$, and $\mathrm{H} 4$ were rejected. Interestingly, content capital and duration had the interaction relationship, indicating that the effect of content capital on site attachment is only valid when the duration is long (see Figure 4). 


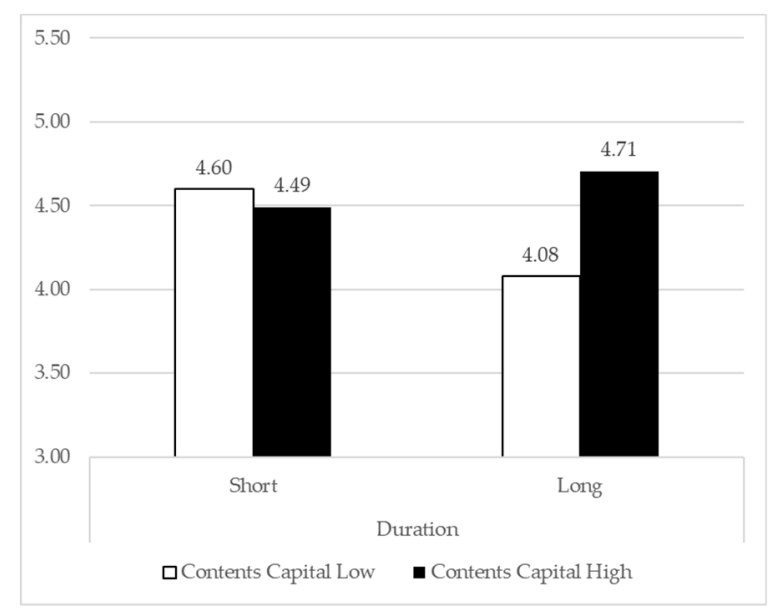

Figure 4. The interaction between duration and content capital.

In addition, social capital and content capital had an interaction effect on attachment. This interaction reveals that the effect of content capital on participants' site attachment was significant when they perceived that they did not have enough social capital (see Figure 5).

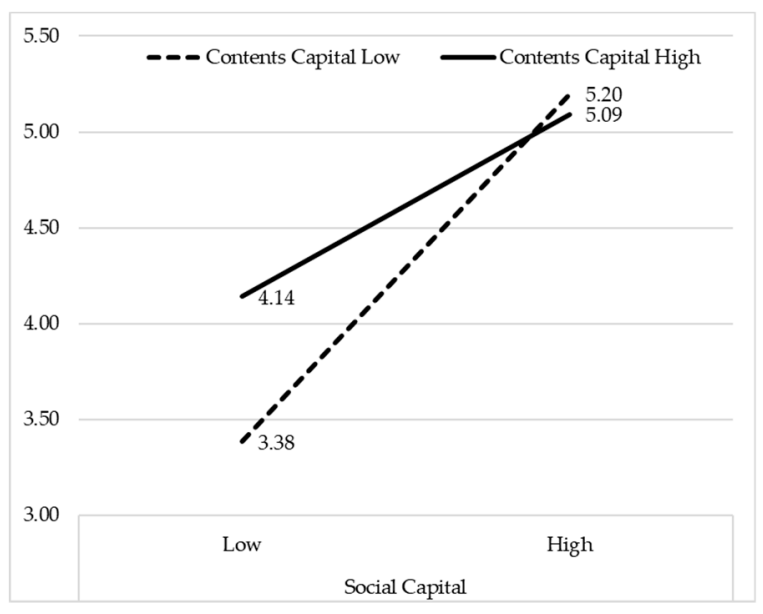

Figure 5. The interaction between social capital and content capital.

More excitingly, three-way interaction (Duration $\times$ Content Capital $\times$ Social Capital) was revealed. To understand this result deeply, we divided the results into two-way conditions depending on duration. Table 3 shows the results. When the participants were exposed to the conditions of short duration, only social capital had an effect on site attachment. On the other hand, when the participants were exposed to the conditions of long duration, all effects were significant. Furthermore, content capital also had a positive effect on site attachment. Two-way interaction was found in the conditions of long duration, which meant that the effect of content capital on site attachment was more salient when social capital was low than when social capital was high. These relationships are shown in Figure 6. 
Table 3. Two-way ANOVAs depending on duration.

\begin{tabular}{ccccccc}
\hline & \multicolumn{3}{c}{ Duration = Short } & \multicolumn{3}{c}{ Duration = Long } \\
\hline & F-Value & d.f. & Sig. & F-Value & d.f. & Sig. \\
\hline Corrected Model & 11.644 & 3 & 0.000 & 20.657 & 3 & 0.000 \\
Intercept & 1645.332 & 1 & 0.000 & 1375.101 & 1 & 0.000 \\
Content capital & 0.990 & 1 & 0.322 & 11.460 & 1 & 0.001 \\
Social Capital & 30.722 & 1 & 0.000 & 40.107 & 1 & 0.000 \\
Content Capital $\times$ Social & 0.134 & 1 & 0.715 & 15.020 & 1 & 0.000 \\
Capital & & 92 & & & 100 & \\
Error & & &
\end{tabular}

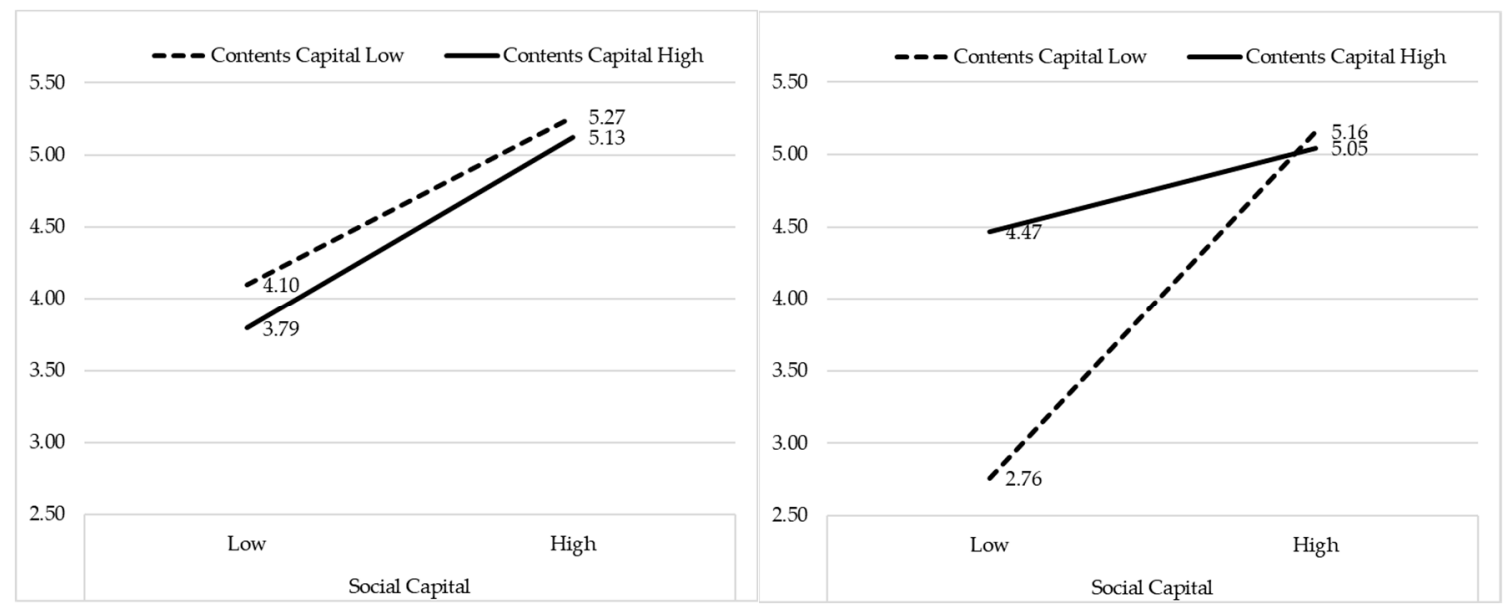

Figure 6. The three-way interaction among duration, social capital, and content capital.

\subsection{Discussion}

The result of experiment 1 shows that attachment in a UGC service site is built through a more complex mechanism than we expected. As hypothesized, social capital is revealed to affect users attached to a UGC service site. However, content capital is meaningful only when duration is long. This result can be interpreted that the amount of content itself is not accepted as important; due to internet channel characteristics, bunches of content can be accessed easily. People may place importance on the duration of building their content, as it reflects users' level of time and sweat investment.

As for social capital, there was a strong relation with attachment regardless of duration. We find that this result reflects internet characteristic of short-lived social relationships. As the majority of relationships shaped in a UGC service site are treated as "instant" relationships, users do not accept the duration as the length of their relationship.

\section{Experiment 2: The Moderating Role of Site Attachment on Continuous UGC Sharing Intention}

\subsection{Research Method}

\subsubsection{Design, Subjects, and Experimental System}

The purpose of experiment 2 is to find the effect of site attachment on continuous site use intention. As we hypothesized, we examined the moderating role of site attachment on continuous UGC sharing intention against new site use intention. The independent variables were current site satisfaction and expected satisfaction with a new site. Two hundred and eleven people participated voluntarily. Their average age was about 30.9 years, and 53\% were male. The same $\$ 5$ reward as experiment 1 was given to all the participants who visited our experimental UGC site. Almost of them (about 96\%) already had UGC sharing experience in online communities. 


\subsubsection{Independent and Dependent Variable}

Site satisfaction is operationalized as how satisfied a participant was with a site. We measured satisfaction of current site and expected satisfaction with a new site. Site attachment is operationalized as the degree to which a site member is fond of, or loyal to, a site. Site attachment, which was the dependent variable for experiment 1, was used as an independent variable. Finally, continuous UGC sharing intention was used as the dependent variable, operationalized as how much a participant intended to continuously use a site. It was borrowed from the previous study [38].

\subsubsection{Control Variables}

Personal UGC sharing experience and picture-related professionalism were controlled. There was no significant difference in these two variables $(\mathrm{F}<1, \mathrm{~ns})$. In addition, the difference in gender and age $(\mathrm{F}<1, \mathrm{~ns})$, and other personal characteristics, was not statistically significant $(\mathrm{F}<1, \mathrm{~ns})$.

\subsubsection{Experimental Procedures}

All participants visited the same virtual UGC site as experiment 1 . Participants were asked to visit the target UGC site, and then click the MY PAGE link. To manipulate the level of site attachment, duration, content capital, and social capital were randomly changed and shown to participants. Next, participants were given the questionnaire, including the measurements of current site satisfaction and site attachment. After they responded to the questions, a new UGC site was introduced. The new site (see Figure 7) was more advanced and popular in terms of the number of members, the number of contents, and site tools such as a search engine and photo editor function. Participants were asked to answer a question about expected new site satisfaction. Finally, participants expressed how much they intended to continue to use the current site without switching to the new site.

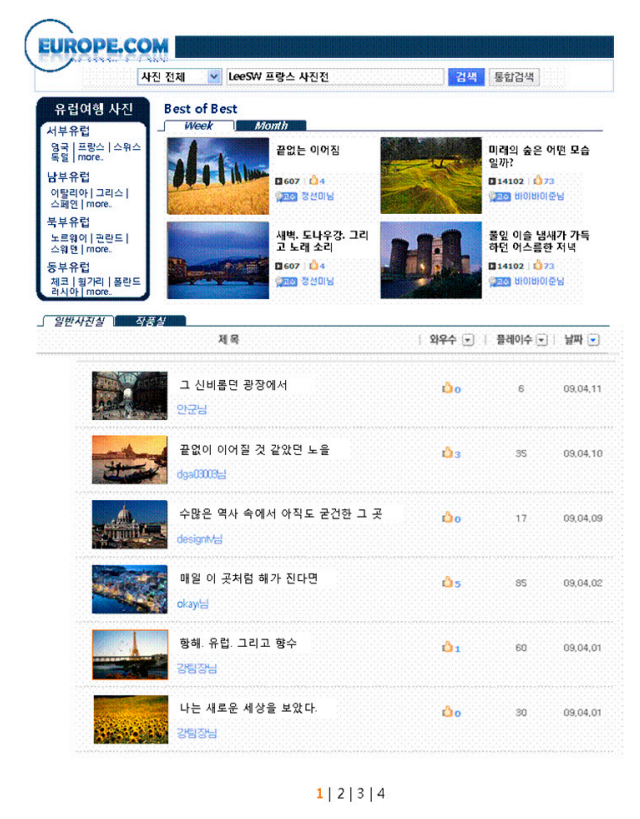

Figure 7. Main image of alternative UGC service site.

\subsection{Research Results}

The participants' responses on the two items, which were designed to check their satisfaction with the current site, were averaged (Eigen Value $=1.76$, Cronbach's Alpha $=0.86$ ). Two items for expected satisfaction with the new site (Eigen Value $=1.79$, Cronbach's Alpha $=0.88$ ) and two items for site attachment $($ Eigen Value $=1.84$, Cronbach's Alpha $=0.91$ ) were also averaged . 
In order to find the moderating role of site attachment, we divided participants into two groups depending on site attachment score. The average of the site attachment score was 4.5 , so participants with responses over 4.5 were in the "strong site attachment" group (Mean $=5.5)$, while participants with responses under 4.5 were in the "weak site attachment" group (Mean = 3.5).

For the purpose of hypothesis testing, we conducted two-group regression analysis. Independent variables were current site satisfaction and expected satisfaction with a new site, and the dependent variable was continuous UGC sharing intention (Eigen Value $=1.38$, Cronbach's Alpha $=0.55$ ). The results are in Table 4 . When site attachment was weak, current site satisfaction was not significant, while expected satisfaction had a strong negative effect on continuous UGC sharing intention. On the other hand, when site attachment was strong, both satisfactions were significant. Specifically, current site satisfaction had a positive effect and expected satisfaction with a new site had a negative effect on continuous UGC sharing intention. Thus, H7 and H8 were accepted.

Table 4. Regression results depending on site attachment.

\begin{tabular}{|c|c|c|c|c|c|}
\hline Model & & Beta & $\begin{array}{c}\text { Standardized } \\
\text { Beta }\end{array}$ & T-Value & Sig. \\
\hline \multirow{3}{*}{$\begin{array}{c}\text { Weak } \\
\text { Site } \\
\text { Attachment }\end{array}$} & (Constant) & 4.153 & \multirow[b]{2}{*}{0.16} & 8.04 & 0.01 \\
\hline & $\begin{array}{l}\text { Current Site } \\
\text { Satisfaction }\end{array}$ & 0.167 & & 1.55 & 0.12 \\
\hline & $\begin{array}{l}\text { Expected Satisfaction } \\
\text { with New Site }\end{array}$ & -0.26 & -0.27 & -2.58 & 0.01 \\
\hline & (Constant) & 5.64 & & 7.74 & 0.01 \\
\hline $\begin{array}{l}\text { Strong } \\
\text { Site }\end{array}$ & $\begin{array}{l}\text { Current Site } \\
\text { Satisfaction }\end{array}$ & 0.23 & 0.23 & 2.38 & 0.01 \\
\hline Attachment & $\begin{array}{l}\text { Expected Satisfaction } \\
\text { with New Site }\end{array}$ & -0.48 & -0.36 & -3.82 & 0.01 \\
\hline
\end{tabular}

\subsection{Discussion}

The result of experiment 2 confirmed former research conclusions that the satisfaction level on current IT systems increases a user's continuous usage intention. Additionally, we confirmed that the expected satisfaction level with an alternative site affects to the continuous UGC sharing intention of the current site regardless of the satisfaction level with current site.

Additionally, it was found that when the attachment level of the current site is low, the satisfaction level with the current site cannot raise a user's continuous UGC sharing intention. This result gives an advanced insight to the service provider that any functional excellence of a UGC service site is useless without the site's attachment of users.

\section{Conclusions}

In this study, we confirmed that the results of former research (i.e., that users' satisfaction is driving continuous usage intention) [38], can be applied to a UGC service site. Additionally, we found that the missing psychological factor-attachment-plays an important role in shaping users' continuous participation intention. This study also concludes that, in the absence of a user's emotional attachment, satisfaction with the current system will not lead to continuous UGC sharing intention. This revelation has important theoretical value as an explanation for why many information systems are neglected in the market despite their superior technologies.

Former studies maintain their position that emotional attachment is formed by satisfying the needs of autonomy, relatedness, and competency [40]. This study has expanded on these former studies by introducing duration as a moderator. However, the result that social capital leads to attachment, regardless of duration, illustrates the characteristics of social relationships formed in an online environment. This result makes an important theoretical contribution by suggesting elements to be considered when research moves its focus from task-oriented IT systems to entertainment-oriented 
IT systems and UGC service sites. By adopting an alternative site in one model, this study provides a new methodology that is fit for the environment in which users have a lot of alternatives.

For UGC service site managers, this study emphasizes the importance of software elements and relationships with other members for locking in current users. UGC service site managers must keep in mind that improving relationships between users through revitalizing their communities and the feedback process is a critical management strategy. In addition, they must consider the strategy of displaying the activity history and contents in a recognizable form at all times because content capital and duration of the site can be effective tools for sustaining their users.

A limitation of this research is the use of a virtual UGC site for the experiments. Even though efforts were made to make the site look like a real site, we could not rule out the possibility that users who meet on a virtual site react differently than users on a real site. The fact that all data were collected at a single point in time also can be a limitation of this research, even though there is little argument on the direction of causality of this research. Additionally, regarding the comparison of a current site with an alternative site, two sites were created consisting of similar characteristics, but we could not exclude the possibility that some users who preferred any of the characteristics of the alternative site (e.g., the search function) produced noise. Studies in the future should expand the types of UGC. It would be a meaningful effort to verify that the results of a study correspond to various UGC transformations. Additionally, it also would be significant if the experiments were conducted in real sites, not in virtual sites.

Despite the above limitations, this research helps identify many potential research opportunities. We propose them in four ways: (1) Extension to offline or organizational context [41]; (2) the moderating effect of personal characteristics such as the level of involvement [42,43], knowledge [44], and regulatory focus [45]; (3) in-depth elaboration of underlying mechanisms between attachment and sustainable usage; and (4) the effect of UGC's other reflexive roles such as self-enhancement or self-presentation for achieving community goals and projects $[46,47]$.

Author Contributions: S.L. designed the model and built the logic for the hypotheses. D.-H.P. analyzed the data and carried out the insights and implementation. Both shaped the research and provided essential feedback and discussion.

Funding: This work was supported by the Ministry of Education of the Republic of Korea and the National Research Foundation of Korea (NRF-2017S1A5A8018751).

Acknowledgments: Do-Hyung Park thanks Yoonhee Hwang, Chaehee Park, and Chanhee Park for insightful and helpful comments.

Conflicts of Interest: The authors declare no conflicts of interest.

\section{References}

1. Wasko, M.M.; Faraj, S. "It is what one does": Why people participate and help others in electronic communities of practice. J. Strateg. Inf. Syst. 2000, 9, 155-173. [CrossRef]

2. Preece, J. Empathic communities: Balancing emotional and factual communication. Interact. Comput. 1999, 12, 63-77. [CrossRef]

3. Brazelton, J.; Gorry, G.A. Creating a knowledge-sharing community: If you build it, will they come? Commun. ACM 2003, 46, 23-25. [CrossRef]

4. Semanjski, I.; Bellens, R.; Gautama, S.; Witlox, F. Integrating big data into a sustainable mobility policy 2.0 planning support system. Sustainability 2016, 8, 1142. [CrossRef]

5. Marine-Roig, E.; Martin-Fuentes, E.; Daries-Ramon, N. User-generated social media events in tourism. Sustainability 2017, 9, 2250. [CrossRef]

6. Preece, J. Online Communities: Designing Usability and Supporting Socialbilty; John Wiley \& Sons, Inc.: Hoboken, NJ, USA, 2000.

7. Dellarocas, C. Strategic manipulation of internet opinion forums: Implications for consumers and firms. Manag. Sci. 2006, 52, 1577-1593. [CrossRef] 
8. Leidner, D.; Koch, H.; Gonzalez, E. Assimilating Generation Y IT New Hires into USAA's Workforce: The Role of an Enterprise 2.0 System. MIS Q. Executive 2010, 9, 229-242.

9. El Sawy, O.A.; Bowles, G. Redesigning the customer support process for the electronic economy: Insights from storage dimensions. MIS Q. 1997, 21, 457-483. [CrossRef]

10. Ogawa, S.; Piller, F.T. Reducing the risks of new product development. MIT Sloan Manag. Rev. 2006, 47, 65.

11. Verona, G.; Prandelli, E.; Sawhney, M. Innovation and virtual environments: Towards virtual knowledge brokers. Organ. Stud. 2006, 27, 765-788. [CrossRef]

12. Gu, B.; Konana, P.; Rajagopalan, B.; Chen, H.-W.M. Competition among virtual communities and user valuation: The case of investing-related communities. Inf. Syst. Res. 2007, 18, 68-85. [CrossRef]

13. Wasko, M.M.; Faraj, S. Why should I share? Examining social capital and knowledge contribution in electronic networks of practice. MIS Q. 2005, 29, 35-57. [CrossRef]

14. Maloney-Krichmar, D.; Preece, J. A multilevel analysis of sociability, usability, and community dynamics in an online health community. ACM Trans. Comput.-Hum. Interact. 2005, 12, 201-232. [CrossRef]

15. Lee, S.; Park, D.-H.; Han, I. New members' online socialization in online communities: The effects of content quality and feedback on new members' content-sharing intentions. Comput. Hum. Behav. 2014, 30, 344-354. [CrossRef]

16. Wellman, B. Computer networks as social networks. Science 2001, 293, 2031-2034. [CrossRef] [PubMed]

17. Ren, Y.; Harper, F.M.; Drenner, S.; Terveen, L.; Kiesler, S.; Riedl, J.; Kraut, R.E. Building member attachment in online communities: Applying theories of group identity and interpersonal bonds. MIS Q. 2012, 36, 841-864. [CrossRef]

18. Schneider, A.; Von Krogh, G.; JäGer, P. “What's coming next?” Epistemic curiosity and lurking behavior in online communities. Comput. Hum. Behav. 2013, 29, 293-303. [CrossRef]

19. Rodgers, S.; Chen, Q. Internet community group participation: Psychosocial benefits for women with breast cancer. J. Comput.-Mediat. Commun. 2005, 10. [CrossRef]

20. Kittur, A.; Suh, B.; Pendleton, B.A.; Chi, E.H. He says, she says: Conflict and coordination in Wikipedia. In Proceedings of the SIGCHI Conference on Human factors in Computing Systems, San Jose, CA, USA, 28 April-3 May 2007; pp. 453-462.

21. Zhu, Y.; Ding, J.; Zhu, Q.; Cheng, Y.; Ma, Q.; Ji, X. The impact of green open space on community attachment-A case study of three communities in Beijing. Sustainability 2017, 9, 560. [CrossRef]

22. Guo, Y.; Zhang, J.; Zhang, Y.; Zheng, C. Catalyst or Barrier? The Influence of Place Attachment on Perceived Community Resilience in Tourism Destinations. Sustainability 2018, 10, 2347. [CrossRef]

23. Tajfel, H.; Turner, J. The Social Identity Theory of Intergroup Behaviour. u: Worchel S. i Austin WG (ur.) Psychology of Intergroup Relations; Nelson Hall: Chicago, IL, USA, 1986.

24. Rheingold, H. The Virtual Community: Finding Commection in a Computerized World; Addison-Wesley Longman Publishing Co., Inc.: Boston, MA, USA, 1993.

25. Blanchard, A.L.; Markus, M.L. The experienced sense of a virtual community: Characteristics and processes. ACM SIGMIS Database DATABASE Adv. Inf. Syst. 2004, 35, 64-79. [CrossRef]

26. Lee, F.S.; Vogel, D.; Limayem, M. Virtual community informatics: A review and research agenda. J. Inf. Technol. Theory Appl. 2003, 5, 5.

27. Coleman, J.S. Social capital in the creation of human capital. Am. J. Sociol. 1988, 94, S95-S120. [CrossRef]

28. Bourdieu, P. The forms of capital. In Handbook of Theory and Research for the Sociology of Education; Richardson, J.G., Ed.; Greenwood: Westport, CT, USA, 1986; pp. 241-258.

29. Wellman, B. Community: From neighborhood to network. Commun. ACM 2005, 48, 53-55. [CrossRef]

30. Blanchard, A.; Horan, T. Social capital and virtual communities. Soc. Sci. Comput. Rev. 1998, 16, $293-307$. [CrossRef]

31. Liao, S.; Chou, E.-Y. Intention to adopt knowledge through virtual communities: Posters vs lurkers. Online Inf. Rev. 2012, 36, 442-461. [CrossRef]

32. Jones, M.A.; Reynolds, K.E.; Mothersbaugh, D.L.; Beatty, S.E. The positive and negative effects of switching costs on relational outcomes. J. Serv. Res. 2007, 9, 335-355. [CrossRef]

33. Burnham, T.A.; Frels, J.K.; Mahajan, V. Consumer switching costs: A typology, antecedents, and consequences. J. Acad. Mark. Sci. 2003, 31, 109-126. [CrossRef] 
34. Baldwin, M.W.; Keelan, J.P.R.; Fehr, B.; Enns, V.; Koh-Rangarajoo, E. Social-cognitive conceptualization of attachment working models: Availability and accessibility effects. J. Person. Soc. Psychol. 1996, 71, 94-109. [CrossRef]

35. Mikulincer, M.; Gillath, O.; Halevy, V.; Avihou, N.; Avidan, S.; Eshkoli, N. Attachment theory and rections to others' needs: Evidence that activiation of the sense of attachment security promotes empathic responses. J. Person. Soc. Psychol. 2001, 81, 1205-1224. [CrossRef]

36. Davis, F.D. Perceived usefulness, perceived ease of use, and user acceptance of information technology. MIS Q. 1989, 13, 319-340. [CrossRef]

37. Moon, J.-W.; Kim, Y.-G. Extending the TAM for a World-Wide-Web context. Inf. Manag. 2001, 38, $217-230$. [CrossRef]

38. Bhattacherjee, A. Understanding information systems continuance: An expectation-confirmation model. MIS Q. 2001, 25, 351-370. [CrossRef]

39. Sivadas, E.; Venkatesh, R. An examination of individual and object-specific influences on the extended self and its relation to attachment and satisfaction. Adv. Consum. Res. 1995, 22, 406-412.

40. La Guardia, J.G.; Ryan, R.M.; Couchman, C.E.; Deci, E.L. Within-person variation in security of attachment: A self-determination theory perspective on attachment, need fulfillment, and well-being. J. Person. Soc. Psychol. 2000, 79, 367-384. [CrossRef]

41. Kwahk, K.-Y.; Park, D.-H. The effects of network sharing on knowledge-sharing activities and job performance in enterprise social media environments. Comput. Hum. Behav. 2016, 55, 826-839. [CrossRef]

42. Park, D.-H.; Lee, J. eWOM overload and its effect on consumer behavioral intention depending on consumer involvement. Electron. Commer. Res. Appl. 2008, 7, 386-398. [CrossRef]

43. Park, D.-H.; Lee, J.; Han, I. The effect of on-line consumer reviews on consumer purchasing intention: The moderating role of involvement. Int. J. Electron. Commer. 2007, 11, 125-148. [CrossRef]

44. Park, D.-H.; Kim, S. The effects of consumer knowledge on message processing of electronic word-of-mouth via online consumer reviews. Electron. Commer. Res. Appl. 2008, 7, 399-410. [CrossRef]

45. Kim, K.-W.; Park, D.-H. Individual Thinking Style leads its Emotional Perception: Development of Web-style Design Evaluation Model and Recommendation Algorithm Depending on Consumer Regulatory Focus. J. Intell. Inf. Syst. 2018, 24, 171-196.

46. Kim, Y.-S.; Park, D.-H.; Park, S.-B. Tariff choice of online contents based on usage goal and self-control: Can I control myself? Internet Res. 2015, 25, 852-867. [CrossRef]

47. Park, S.B.; Park, D.H. The effect of low-versus high-variance in product reviews on product evaluation. Psychol. Mark. 2013, 30, 543-554. [CrossRef] 